\title{
A construção do diagnóstico do autismo em uma rede social virtual brasileira*
}

\author{
Francisco Ortega ${ }^{1}$ \\ Rafaela Zorzanelli ${ }^{2}$ \\ Lilian Kozslowski Meierhoffer ${ }^{3}$ \\ Celita Almeida Rosário ${ }^{4}$ \\ Clarissa Freitas de Almeida ${ }^{5}$ \\ Bárbara Fonseca da Costa Caldeira de Andrada ${ }^{6}$ \\ Beatriz da Silva Chagas ${ }^{7}$ \\ Clara Feldman ${ }^{8}$
}

ORTEGA, F. et al. The construction of the diagnosis of autism in a Brazilian virtual

community. Interface - Comunic., Saude, Educ., v.17, n.44, p.119-32, jan./mar. 2013.

This article presents preliminary results from ongoing research about autism in Brazilian virtual communities. We investigated public opinion about autism in the virtual communities dedicated to this issue. Public opinion about a medical condition directly influences the sick person's experience and the experiences of her caregivers and family. The results describe the social representations of the users - mainly parents and caregivers of autistic children - about the supposed causes of autism, the forms of treatment, the forms of activism and the rights of autistics and the ambivalent use of medical knowledge, which is frequently endowed with the capacity of disclosing the disease, but which is also resisted in favor of lay knowledge of parents and caregivers based on their daily experience with the autistic people.

Keywords: Autistic Disorder. Public opinion. Social networking. Psychiatric disorders.
Este artigo apresenta alguns resultados de uma pesquisa realizada em uma rede social virtual brasileira, com o tema do autismo. Investigou-se a opinião pública sobre o autismo nessa rede, por meio de suas comunidades ligadas ao assunto. A opinião pública sobre determinada condição médica traz consequências diretas sobre a experiência do doente e sobre as pessoas implicadas em cuidar dos pacientes acometidos. Os resultados apontam algumas direções a respeito das representações dos usuários sobre as supostas causas da doença, os métodos de tratamento, as formas de ativismo e de busca de direitos dos portadores, e os usos paradoxais do conhecimento médico, ao qual se atribui a possibilidade de desvendar a doença, e, ao mesmo tempo, é alvo de resistência de pais e cuidadores, que priorizam o conhecimento proveniente de sua experiência cotidiana com os autistas.

Palavras-chave: Transtorno autístico. Opinião pública. Rede social. Transtornos psiquiátricos.

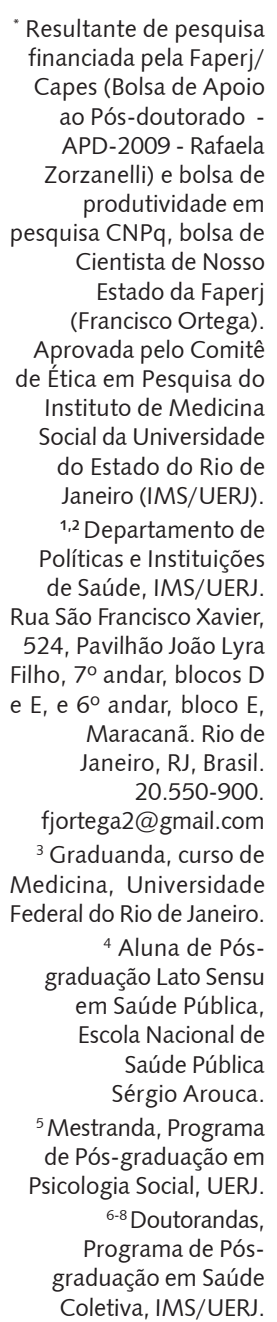

Resultante de pesquisa anciada pela Faperj/ ao Pós-doutorado APD-2009 - Rafaela orzanelli) e bolsa de produtividade em Cientista de Nosso Estado da Faperj (Francisco Ortega). ética em Pesquisa do Instituto de Medicina social da Universidade do Estado do Rio de 1,2 Departamento de Políticas e Instituições de Saúde, IMS/UERJ. a São Francisco Xavier, Filho, $7^{\circ}$ andar, blocos D $E$, e $6^{\circ}$ andar, bloco $E$, Maracanã. Rio de iro, RJ, Brasil.

fjortega2@gmail.com

Graduanda, curso de Federal do Rio de Janeiro. Aluna de Pósem Saúde Pública, cola Nacional de Saúde Pública Mestranda, Programa de Pós-graduação em

6-8 Doutorandas, raduação em Saúde Coletiva, IMS/UERJ. 


\section{Introdução}

A pesquisa sobre o impacto da internet na experiência de portadores de doenças - sobretudo aquelas envoltas em incertezas quanto à etiologia - é assunto em plena expansão no campo do conhecimento sociológico em saúde (Conrad, Stults, 2010; Barker, 2008; Bromm, Tovey, 2008; Miah, Rich, 2008; Schaffer, Kuczynski, Skinner, 2008; Berger, Wagner, Baker, 2005; Broom, 2005; Fox, Ward, o'Rourke, 2005a, 2005b; Seale, 2005; Gandchoff, 2004; Gillet, 2003; Blumenthal, 2002; Hardey, 1999).

Certamente, a emergência dessas pesquisas se situa em contexto recente e debitário do surgimento e popularização da internet, ocorrida em meados de 1990. Isso porque o advento da internet, e da possibilidade de interação anônima e virtual entre seus usuários, alterou a experiência da doença para muitos dos pacientes e/ou de seus cuidadores. Fora do mundo virtual, a experiência da doença era tipicamente privada, discutida apenas com o médico e a família, sem a comunicação com outros sofredores da mesma condição. Desde as possibilidades abertas pelo contato virtual, pacientes e os coparticipantes de sua condição clínica têm exercitado a possibilidade de partilhar vivências com outros portadores. O público crescente desses usos da internet é, sobretudo, aquele formado por pessoas que padecem de doenças estigmatizadas - controversas em sua etiologia, e ainda não decifradas pela biomedicina -, condições crônicas e debilitantes (Conrad, Stults, 2010).

Fontes disponíveis como blogs, weblogs, páginas pessoais em redes sociais e grupos de apoio virtual produzem conhecimento baseado na experiência vivida de cada paciente, conhecimento esse que é trocado, partilhado, dividido e multiplicado nas formas diversas de contato virtual, criando o que Collins e Evans (2002, p.238) chamaram de especialistas baseados na experiência, cujo conhecimento se estrutura no cotidiano e nas limitações que esse lhes impõe. É gerada uma nova economia das informações sobre as doenças, meios de lidar com ela, contraposições de opiniões dos médicos que acompanham os pacientes/usuários das redes virtuais. Blumenthal (2002) sugere que as interações on line dos pacientes diminuem a autoridade e exclusividade da figura do médico como transmissor de informações sobre doenças. Dessa forma, as modalidades de contato entre pacientes encontradas na internet nos permitem acesso a: informações que compõem o mosaico da opinião pública sobre doenças, os modos como os pacientes/usuários lidam com suas condições de saúde, os usos diversos que as redes virtuais permitem em termos de divulgação de teorias científicas, informações médicas, conhecimento baseado no cotidiano e formas de ativismo em saúde.

A popularização das informações científicas e o modo como são recebidas e utilizadas entre os meios leigos - que são, frequentemente, os meios em que se incluem pacientes e cuidadores - podem afetar a própria formulação de políticas públicas. Ou seja, a forma como o conhecimento científico é divulgado e popularizado retroage sobre a formulação de políticas e sobre o próprio modo como aquela doença é socialmente concebida e representada. No limite, a opinião pública acerca de determinadas condições clínicas e o modo como são socialmente percebidas pelos diferentes atores - leigos, indivíduos que não têm contato com o autismo, profissionais de saúde, pais, cuidadores, gestores trazem consequências diretas sobre a experiência do doente e das pessoas diretamente implicadas em seu cuidado. Além disso, interferem na legitimidade social daquela doença, isto é, em quanto ela é considerada merecedora de cuidado pelos profissionais e pelos pares com quem o doente se relaciona, e, no limite, quanto ela deve ser amparada pelo sistema público de saúde.

\section{Autismo e internet}

No caso específico do autismo, Ortega (2009) analisa quanto a internet foi um ponto de virada na formação de grupos de pacientes que partilham uma característica corporal ou mental. Um exemplo disso é a primeira lista on line de pais de autistas, considerada uma forma de self-advocacy, ou seja, de campanha em prol de interesses de um grupo - a Autism and Developmental Disabilities List (Autism List), que contribuiu para a promoção da Applied Behavioral Analysis (ABA), como forma de terapia direcionada às crianças autistas.

O foco no tratamento e cura do autismo colocado em marcha por essa lista deu origem a um forte movimento de crítica proveniente de adultos autistas que se sentiam ignorados e incompreendidos. $O$ 
resultado foi a criação da lista encabeçada por Jim Sinclair e Donna Williams, a Autism Network International (ANI), no ano de 1992. Essa lista foi corroborada por outra, em 1994, a Autism Network International Listserv (ANI-L). Embora pessoas não autistas pudessem aderir a essa última lista, toda decisão deveria ser tomada por autistas (Orsini, Smith, 2010; Orsini, 2009; Chamak, 2008; Silverman, 2008a). A ideia central "by autistics for autistics" (por autistas e para autistas) centralizava o principal valor da ANI, epitomizado no emblema "nothing about us without us" - nada sobre nós sem nossa participação (Charlton, 2000; Shapiro, 1993), obras de relevância na tradição dos Disability studies (estudos sobre deficiência) e do movimento dos portadores de deficiência.

Há uma crescente atenção da pesquisa em ciências sociais a respeito dessas questões, sobretudo em se tratando de análises etnográficas (Wilson, Peterson, 2002; Miller, Slater, 2000), sendo a internet um cenário destacado da construção de sentido para o diagnóstico e para a experiência de ser autista ou de ser parente de um autista. A internet vem se tornando um espaço essencial para o desenvolvimento da personalidade de pessoas com autismo (Kenway 2009; Biever, 2007; Blume, 1997), e um número destacado de estudos empíricos tem sido feito sobre o autismo no ciberespaço (Clarke, van Amerom, 2008, 2007; Davidson, 2008; Brownlow, O'Dell, 2006; Jones, Meldal, 2001; Jones, Zahl, Huws, 2001).

Dentre as pesquisas qualitativas sendo conduzidas a respeito do autismo, destacam-se: as autobiografias escritas por pessoas com autismo, os depoimentos de pais e familiares, e dos profissionais de saúde (Hacking, 2009; Chamak et al., 2008; Davidson, 2008, 2007; Osteen, 2008; Ariel, Naseef, 2006). Outras pesquisas etnográficas examinam a construção da identidade por indivíduos autistas (Bagatell, 2007; Jurecic, 2007). O rol de assuntos tratados nessas investigações abrange assuntos como: a compreensão de pais e pacientes sobre a condição autista; diferenças perceptuais e suas implicações para o indivíduo autista; expressão e manejo da emoção; particularidades da sexualidade e dos relacionamentos amorosos, bem como o papel da internet e das novas tecnologias de comunicação na interação entre esses indivíduos.

As comunidades virtuais que se reúnem em razão do autismo tornaram-se participantes ativos tanto da disseminação de achados de pesquisas quanto do direcionamento do apoio financeiro a algumas delas, interferindo, muitas vezes, na constituição de políticas públicas e lutas por direitos ao doente (Orsini, Smith, 2010; Orsini, 2009; Ortega, 2009; Chamak, 2008; Silverman, 2008a, 2008b).

Nossa pesquisa se insere nesse âmbito do estudo da construção do diagnóstico do autismo por meio da opinião de usuários de uma rede social virtual brasileira, levando em consideração informações que nos permitissem avaliar como o diagnóstico de autismo era compreendido, avaliado, manejado e debatido. Um tema que impulsionou a proposição dessa investigação é o fato de o autismo estar envolvido em um debate bastante particular, que é o da chamada "neurodiversidade" - indivíduos diagnosticados com a síndrome de Asperger, um tipo especial de autismo de alto funcionamento, são os principais atores desse movimento. Seus portadores afirmam que sua condição é um resultado de conexões neurológicas diferentes das conexões da maioria das pessoas, mas que, nem por isso, tratar-seia de uma doença a ser curada, mas, sim, de uma diferença humana a ser respeitada, tal como a diversidade sexual ou étnica (Baker, 2011; Eyal et al., 2010; Ortega, 2009; Singer, 1999). Em outras palavras, para eles, o autismo não seria uma doença, mas um modo de funcionamento cerebral diferente, e como tal, mereceria o respeito e a liberdade de existir sem necessidade de tratamento médico. É importante lembrar que esses indivíduos estão situados no extremo mais funcional do espectro do transtorno, o que é uma situação muito diferente da vivida pela maioria das crianças autistas.

$\mathrm{Se}$, por um lado, o respeito à diversidade Asperger é defendido por uns, por outro, é considerado uma afronta, já que oferece argumentos para que os órgãos estatais responsáveis pela saúde dos cidadãos se recusem a financiar os tratamentos.

Dada a expressividade desses debates fora do Brasil e a velocidade de difusão de informações na internet, fomos movidos por algumas perguntas: a rede social seria, também no Brasil, um ponto de contato para troca de informações, tal como ocorre em outros países? O debate em torno do tema da neurodiversidade, pregnante internacionalmente na atualidade, apareceria nos usuários da rede social brasileira? Que tipo de hipóteses etiológicas apareceriam nos debates virtuais? Haveria avaliações ou preferências dos usuários por determinadas terapias? O tema do "orgulho autista" mobilizaria também os grupos brasileiros? 


\section{Por que pesquisar uma rede social virtual?}

Fontes diversas podem ser usadas para investigar a opinião pública sobre uma doença, tais como: a mídia impressa diária e a mídia televisiva, os profissionais envolvidos na questão, os leigos. A pesquisa em questão teve como alvo os usuários das redes sociais virtuais, e, especificamente, o orkut, que era, no momento de coleta dos dados, a rede social mais popular no Brasil, criada em 2004.

As redes sociais virtuais permitem partilhar informações das mais diversas formas - textos, arquivos, imagens, fotos, vídeos, e, sobretudo, pequenos textos postados, chamados scraps, constituindo um material rico para a análise de representações, ideias e opiniões dos usuários. Nessa rede formam-se grupos por afinidades, que são as "comunidades", dentro das quais criam-se tópicos - temas que disparam debates entre os usuários.

Além do papel das mídias on line no ativismo em saúde, a internet oferece condições bastante particulares: ela cria uma sensação de intimidade por meio da condição de anonimato, e, assim, pessoas que possivelmente não se encontrariam, partilham a experiência de ter uma doença específica ou de ser parente ou cuidador de um doente, podendo interferir, pela força do agrupamento virtual, nos rumos das pesquisas sobre doenças, nas políticas públicas criadas, e em outros aspectos.

Coletar dados de uma fonte que muda a todo tempo pelo acréscimo e retirada de postagens é uma tarefa desafiadora, e, por isso, foi necessário construir instrumentos que pudessem preservar o mínimo de confiabilidade ao material. Por outro lado, a instabilidade da fonte e o fato de que ela seja cotidianamente permeável à mudança nos dão a possibilidade de verificar a difusão de certas ideias debatidas, nacional e internacionalmente, sobre o autismo praticamente ao mesmo tempo em que elas ocorrem, de observar o modo como adentram os debates brasileiros, e ganham um tom próprio.

\section{Métodos}

Esse projeto de pesquisa foi aprovado pelo Comitê de Ética em Pesquisa do Instituto de Medicina Social da UERJ. A metodologia envolveu a coleta de tópicos e postagens em comunidades do orkut ligadas ao tema do autismo. Foram utilizados instrumentos confeccionados pelo grupo de pesquisa, no qual constam tanto a caracterização das comunidades (moderador, caracterização, número de membros etc.) e o recorte e colagem dos scraps dos tópicos das comunidades relacionados ao tema do autismo (Instrumento 1). Utilizamos um programa de software idealizado por um dos pesquisadores para procedimentos de recorte e colagem dos scraps dos tópicos previamente selecionados como pertinentes à amostra, dentro de cada comunidade também pré-selecionada. Somente os tópicos absolutamente fora da temática (venda de produtos para emagrecer, propagandas de produtos eróticos) foram retirados dessa contabilidade. Posteriormente, realizou-se, pelo método da análise de conteúdo, uma tabulação dos principais temas ocorrentes nas postagens (Instrumento 2). Essa tabulação, inicialmente realizada em formato Word, foi transferida para uma planilha no formato Excel, onde a contabilidade da ocorrência dos temas por comunidade (e por cada um de seus tópicos utilizados) é realizada automaticamente (Instrumento 3).

Foram coletadas nove comunidades e, ao todo, cento e noventa tópicos (ou fóruns de discussão), totalizando quinhentos e trinta scraps. As nove comunidades foram escolhidas a partir da palavra de busca "autismo", dentre as primeiras vinte ocorrências. Os pesquisadores tiveram o cuidado de escolher comunidades com número de usuários em torno de mil ou mais. A coleta das informações ocorreu entre setembro de 2009 e dezembro de 2010.

Uma mesma postagem poderia ser classificada em mais de uma categoria de análise, contabilizando menções, por exemplo, à categoria busca de contato (com outros usuários) e estigma, ao mesmo tempo. As categorias de análise totalizaram setenta temas, o que demonstra dois de nossos interesses: 1) registrar os temas ocorrentes, independente de sua frequência, com o objetivo da análise qualitativa; 2) registrar quaisquer tipos de temas ocorrentes e correlacioná-lo(s) posteriormente com sua frequência de ocorrência, no intuito de constituir dados quantitativos. Não se pode dizer que nossa amostra comunidade reflita a dinâmica geral das discussões sobre autismo na rede social pesquisada. Apenas 
podemos sugerir que, a partir das comunidades escolhidas, alguns conteúdos temáticos se destacam, e compreendê-los pode ampliar nossa percepção sobre como o diagnóstico de autismo é recebido, manejado, articulado e construído entre aqueles usuários.

Como não se poderia saber de antemão quanto um tema seria frequente, todos os que configuravam uma unidade temática, sob a análise coletiva dos pesquisadores, foram transformados em categorias de análise, ainda que algumas delas sirvam apenas para que se conheçam os assuntos, interesses, usos e trocas ocorridos por meio dessa rede virtual.

As categorias envolviam temas como: estigma; explicações para o autismo formuladas pelos usuários (genética, cérebro, metais pesados, vacinas, nutrição, dentre outros); terapias como a Applied Behaviour analysis (ABA), Treatment and Education of Autistic and related Communication handicapped Children (Teacch), Picture Exchange Communication System (PECs), Son-Rise; educação especial; avaliação dos pais em relação ao serviço oferecido em escolas inclusivas; convocação à luta pelos direitos dos autistas.

\section{Resultados}

Diante das análises realizadas, podemos apontar as tendências dos resultados. Como a quantidade de dados foi grande, apresentaremos aqui algumas das temáticas recorrentes.

Uma das principais funções dos fóruns de discussão da rede é a busca de contato para troca de informação sobre a doença e para apoio (emocional, profissional e institucional). A troca de informações sobre a doença envolvia a solicitação de contato com outros participantes para disponibilização de informações sobre diagnóstico, formas de lidar com a pessoa autista, indicação de especialistas a serem procurados. Alguns exemplos são apresentados abaixo. Neles, poderemos encontrar algumas postagens que são respostas às perguntas realizadas em postagens

${ }^{9}$ Todas as transcrições de postagens têm os nomes dos usuários alterados, mas são mantidas a ortografia utilizada, no que se refere ao uso da língua portuguesa. Quando o usuário utiliza o recurso das fontes maiúsculas, assinalamos esse uso com a observação em parênteses (maiúscula no original), e mantivemos as letras em minúsculas/ maiúsculas, para adequação ao formato do texto acadêmico. Os erros ortográficos ou de uso formal da língua foram mantidos. anteriores ${ }^{9}$.

Oi. Tenho 4 filhos e a Maria é autista. Ela tem 12 anos gosta de balançar ouvir música e também gosta de ver eu lavar as louças [...] A escola mais próxima é longe e muito cara e não tenho condições de pagar e muito obrigado pela sua atenção.

Precisamos nos ajudar. Nessas comunidades temos famílias de todos os Estados e de vários países. Mts se sentem perdidos e gostariam de ter amigos por perto pra trocar experiências, informações e mesmo pra ter alguém a quem recorrer numa hora de aperto, eu sou uma dessas gostaria de conhecer pessoas que tenham filhos autista e que morem perto de mim, para poder nos ajudar, e às vezes desabafar.

E quando eles batem nos pais? (maiúscula no original). Peço aos familiares de autistas um conselho: o que é melhor fazer quando eles querem bater ou morder os pais ou irmãos? [...].

Eu sou irmã de um altista... realmente ele bate nos familiares... não sei se com seu filho dá certo...mas não custa tentar... fale pra ele mesmo que ele não entenda... "olhe no meu olho, isso não pode" [...] 
É frequente a presença de postagens com testemunhos dos pais, que relatam a via crucis percorrida para o diagnóstico, partilham possíveis benefícios obtidos tanto em termos de direitos de saúde quanto no que se refere a tratamentos. Ainda nesse contexto, chama a atenção o fato de que são sobretudo os pais e cuidadores, ou seja, não especialistas, que respondem com mais frequência às postagens, divulgando informações médicas, pesquisas e condutas de tratamento com as quais eles tiveram boas ou más experiências. No processo de troca de informações, os principais personagens são os pais e parentes (irmãos ou irmãs, tios ou tias) de autistas. Profissionais de educação também aparecem como fornecedores de informação sobre o autismo. Algumas postagens podem esclarecer essas observações:

Querida tudo bem? olha só eu acho que existem varios graus de autismo, o meu sobrinho por exemplo ja foi descoberto aos 5 anos de idade, ele nunca teve problemas ao se enturmar com outras crianças, muito pelo contrario. [...]

Oi. Espero poder te ajudar com o pouco de experiência que tenho com autistas. Ano passado tive um aluno autista, não fala e deficiente visual (ele tinha 14 anos). A mãe faleceu em 2004 e por muitas vezes sussurou "mama" e chorava muito. Isso acaba com a gente, É muito triste vc ver isso e não poder fazer nada. O que fiz com ele foi me sentar no chão, tentar colocá-lo entre minhas pernas e fazer um carinho. Claro, que nas $1^{\text {as }}$ vezes ele não aceitou o contato físico, me empurrava, me batia mas aos poucos fui ganhando a confiança dele e consegui fazer com que ele deixasse que o acalmasse através do tato. Foi uma experiência muito enriquecedora. [...]

Frequentemente, observaram-se referências a informações sobre o autismo em diferentes mídias, como: matérias impressas publicadas em revistas, menções à filmografia sobre o autismo, a outras comunidades do orkut sobre o tema, matérias veiculadas na televisão, sites e blogs sobre o assunto, vídeos no site Youtube. Os usuários demonstraram manejar e trocar informações sobre matérias veiculadas em diferentes formas de mídia, como nos casos abaixo:

Olá pessoal sou mãe de uma criança Autista João, de 5 anos, coloquei um video dele no You Tube, é muito interessante a forma que ele aprende e observa as coisas, serve muito para vocês pais e amigos de pessoas especiais e observarem que o comportamentos é quase parecido um do outro, e observamos também que não estamos só nesta luta diária.

Ola tenho filmes que falam sobre autismo, conta a historia de familias lutando para o desenvolvimento de seus filhos..mto bons!!! quem tiver interesse é só entrar em contato pelomsnxxxx@XXX.com.br.bjs

Reportagem. Atenção Assista o Datena amanhã às 07:00h da manhã e depois às 17:00h!!! Reportagem da nossa luta com os autistas e os descasos!!! Bjs (maiúscula no original)

Reportagem na tv $A B C D$. sabado 13 de junho as 10:00 h. (Programa de entrevista com $1 \mathrm{~h}$ de duração Dia do orgulho autista 18 de junho (maiúscula no original) =. Divulgação da $A$ C O R D E M ! Associação de Apoio aos Autistas Correlatos e Deficientes Mentais. Prestigiem os primeiros frutos de nossa luta! Vamos lá pessoal. Acordem (maiúscula no original)! Janaína

Movimento. TVE 08/06. Discussão sobre autistas (maiúscula no original). Amanhã, dia 08.06.2009, a TVE irá apresentar em seu programa Sem Censura, às 16:00hs, uma discussão sobre autistas. Com vários profissionais do assunto. 
Além disso, é notável que, nas comunidades pesquisadas, não há somente divulgação de informações, mas a própria informação é tratada como produto - cursos, manuais, vídeos didáticos e outros materiais são ali comercializados.

Curso de formação no TEACCH. Olá amigos.

Entre os meses de setembro e dezembro o (nome de instituição) estará oferecendo o II Curso de Formação de Educadores no Programa Teacch (maiúscula no original).

Conferência com Joana da Silva - Mãe equatoriana, radicada nos EUA, que recuperou seus dois filhos com autismo utilizando medicina integrativa e homeopatia. Vejam o site dela: www.oiwejraoidjoa.org

No campo dos direitos de saúde, encontramos convocações pela luta por benefícios de saúde, e a oferta de assessoria para elaboração de processos judiciais junto a órgãos públicos para aquisição de benefícios, além da mobilização para participação de movimentos como o orgulho autista (passeatas, encontros reais em diferentes cidades, e outros). A proposição de projetos de lei de proteção à pessoa autista, ainda que pouco expressiva, também aparece. Essa tendência dos dados analisados está em consonância com a literatura internacional que aponta a organização de pacientes em meio virtuais em prol de seus direitos civis, o que configura uma nova modalidade de ativismo em saúde (Barker, 2008; Epstein, 2008; Gillet, 2003; Chamak, 2008).

Vitória! (1/2) Para conhecimento de todos: "Não sei se todos aqui sabem mas, ontem de manhã (02/06), o caso do meu irmão João foi julgado em segunda instância aqui no Tribunal de Justiça de SP e graças a Deus e ao advogado do meu irmão, todos os desembargadores foram unânimes em votar a favor do caso do meu irmão. Desde ontem, o Estado voltou a estar obrigado a pagar o tratamento do meu irmão na clínica. Sei que todos aqui estão passando pelo mesmo "perrengue" e muitos lutam por uma vaga em uma clínica decente para seus filhos, netos e irmãos. [...]

Benefícios para portadores de autismo. Marta, resido em XX - S.Paulo, XXX. Lutei durante cinco anos e consegui tratamento especializado para meu filho Mário - 25 anos. Aqui no estado de São Paulo existe uma Ação Civil Pública onde beneficia portadores de Autismo para tratamento em clínica especializada e estava engavetada desde 2001. A Ação foi muito bem elaborada pela promotoria pública e caso o estado não cumpra, paga multa diária altíssima. Como no meu município e toda região não existe tratamento especializado gratuito, o estado está custeando todo o tratamento. Acho muito importante que as promotorias lutem pelos direitos de nossos filhos. Se precisar de algo, me escreva. Estou à disposição para ajudar no que for necessário. Um abraço.

Ação na justiça para tratamento de autista. Marta tenho um filho autista de 13 anos, que está em uma escola especial, mas não é especializada em autistas [...] eu gostaria de saber como você entrou com esta ação para o governo bancar um tratamento especializado para seu filho, moro no rj e sinto que meu filho está precisando muito de ajuda, por favor me oriente, muito obrigada, um grande abraço, Miriam.

Dia Mundial do Autismo. Dia 2 de Abril é o Dia Mundial da Conscientização do autismo (maiúscula no original) Vamos fazer barulho!!!!!!!! A ADEFA - Associação em defesa do autista (maiúscula no original) - junto com o apoio de outras organizações, estará promovendo um encontro com passeata na Praça XV, RJ - em frente as barcas às 10:00hs. Leve toda a família, amigos, avós, titios, padrinhos, terapeutas... Vamos nos mobilizar e chamar atenção para nossas crianças! Vista-se de branco! Vista uma camisa com foto do seu filho! Vista uma camisa sobre autismo, ou da sua ONG, ou da sua instituição! Movimente- 
A CONSTRUÇÃO DO DIAGNÓSTICO DO AUTISMO EM UMA REDE SOCIAL ...

se!! Se quiser levar faixas, cartazes, balões, fantasias, materiais... Essa é a hora! Espero por vcs lá!!"

Deverá ser um grd evento! Conseguimos entrar no site do Autism Speak, na parte onde os países divulgam seus eventos: Brasil está lá (maiúscula no original) !!! http:// www.worldautismawarenessday.org/site/c.egLMI2ODKpF/b.3917085/k.8FDB/ Event_Schedule.htm

* Conseguimos um avião para rodar o Rio de Janeiro com uma faixa enorme escrito:

Autismo é tratável!!* [Estamos quase conseguindo uma autorização para colocar uma faixa de 20 metros no Cristo Redentor: escrito Tb: Autismo é tratável!

* Na passeata estamos levando mais de 1000 balões para serem soltos nos três poderes: legislativos, judiciário e executivo - e em cada conjunto de balões estará levando um cartaz: com várias frases (maiúscula no original)

No campo das terapêuticas ligadas ao autismo, observamos a menção a métodos diversos, como o método TEACCH, Son-Rise, PECs, ABA, integração sensorial. Em menor frequência, aparecem menções a terapêuticas tradicionalmente ligadas aos campos dos transtornos psicológicos, como a psicanálise e a psicologia cognitivo-comportamental.

Gostaria muito de saber desse novo método ABA. Meu sobrinho tem 5 anos e também não fala.... me ajude por favor. (maiúscula no original)

Programa Son-rise (maiúscula no original). Alguém já participou efetivamente deste programa?? Como aplicador, paciente ou pai?? O que vcs podem me dizer??? é efetivo?

TEACCH. Oi, Ana ... Li e respeito muito sua opinião, pois acredito que o método TEACCH tal qual como foi concebido e que ainda por muitas instituições é trabalhado deste modo, torna realmente os educandos uns legitimos robôs, pois tem caráter e segue a linha comportamental.

A ideia de que o método teacch robotiza é tão equivocada quanto a ideia de que o autista vive em seu próprio mundo. Quem já não ouviu que o autista é aquele que vive em uma redoma de vidro? Ou que todo autista é aquele que se balança de um lado para o outro?

Cognitivo Comportamental X Psicanálise. Gostaria de saber a opinião dos participantes desta comunidade sobre estas abordagens. Vai de acordo com o indivíduo (adaptação)? Alguém conhece alguma pesquisa/ estatística que aponte para algum caminho com maior sucesso?

A análise das postagens nos permitiu inferir uma postura bastante pragmática por partes dos usuários - que, em sua imensa maioria, é composta por pais ou cuidadores: as terapias mais endossadas são aquelas que funcionam com resultados mais imediatos e mais relacionados ao ganho de autonomia (ainda que mínimo) por parte do paciente. Uma terapia que funciona, ao menos no contexto pesquisado, é aquela que amplia o estado de bem-estar físico e comportamental dos portadores, e sua autonomia possível.

No que se refere ao tema das explicações da doença, podemos destacar dois eixos de problematização notáveis nos dados: um deles é o debate se o autismo é curável/tratável ou não; o outro é a discussão em torno de possíveis agentes causadores, como: as vacinas, a imunidade, a ingestão de metais pesados. Esses dois eixos que perpassam o debate acerca das possíveis causas do autismo aparecem nos exemplos a seguir: 
vacina $x$ autismo. artigo no Jornal do Brasil de hoje relacionando mercurio contido nas vacinas brasileiras e autismo....http://jbonline.terra.com.br/extra/2008/07/12/ e120714821.html

Realmente para o Autismo ainda não existe uma causa específica, há muitos estudos científicos sobre suas causas porém nada comprovado. A única coisa q já foi comprovada é uma pequena "lesão" no cerebelo da criança. Algumas linhas psicológicas como a Psicanálise acreditam q uma das causas é uma falta de desejo pela criança já na barriga e problemas familiares, porém isso apenas é uma das tantas suposições q ouvimos por aí...até pq, se pararmos para pensar, há mtttsss crianças q foram super desejadas, bem tratadas e há outras q não foram desejadas, não vivem numa estrutura saudável, como por ex. crianças q nascerem por um "acidente", q sofreram tentativas de aborto, vivem na rua....e em nenhum dos dois casos se apresentam com autismo....logo eu tbm não creio nessa divagação. [...]

Autismo é tratável (negrito no original). Queridas, muito já esta sendo comprovado sim, como origem do autismo, aqui no Brasil a gente ainda comunga uma escola atrasada, que ensina nas faculdades de psicologia a teoria psicótica de que as mães tem mal maternagem. Pura bobagem, mas que sustenta muito psicanalista...rsrsrsr. Temos já, achados de marcadores genéticos de mutações bem definidas, ligação intestinal (nódulos linf Dr.Wakefield), todos os médicos DAN do mundo sabem que a ligação é do sistema imunológico, com marcadores genéticos, mas com desencadeador ambiental. Vacinas com thimerosal no 3 mundo........]. Autismo é tratável sim. Beijos Mariana

Ana, desculpe o atraso em te responder, mas vc precisa saber urgentemente o que esta acontecendo em todo mundo. Só agora li sua msg que o autismo não tem cura e que os tratamentos biológicos não são necessários. Vc esta enganada e eu peço até licença pra te falar isso. [...] vc esta redondamente enganada sobre cura e sobre tratamentos biomedicos. Se vcs fizerem uma pesquisa vão encontrar muitos autistas recuperados, principalmente fora do Brasil. Vc conhece o Sonrise? Usamos este método que é maravilhoso além dos tratamentos biomédicos.

Ainda nesse contexto de debate sobre as possíveis causas do autismo e seu caráter tratável ou não, destaca-se o acesso dos pais a informações supostamente relacionadas a pesquisas científicas sobre o autismo. A rede social se transforma em um meio de difusão dos "achados da ciência".

É reconhecido como medicamente tratável. Notícia quentíssima:

A Escola Americana de Medicina Genética - ACMG - estabeleceu procedimentos de práticas clínicas, a serem seguidas por geneticistas clínicos, para determinar a etiologia dos casos de ASD tanto para tratamento quanto para diagnóstico. Hj já existem bio-marcadores seguros, rotineiros e eficazes para se tratar o autismo! http://www.xxxx

Estudo indica que crianças autistas poderiam aprender através de estereótipos . [...] “Um dos principais problemas das crianças autistas é que são incapazes de entender por que as outras pessoas fazem determinadas coisas: quais são suas motivações ou o que estão pensando ou sentindo", disse a professora Uta Frith, do University College London (UCL), que desenvolveu a pesquisa. [...]

Descoberta enzima que pode combater o autismo. Cientistas americanos conseguiram reverter os sintomas de atraso mental e de autismo em cobaias inibindo uma enzima que afeta as conexões entre as células cerebrais. Em uma série de experiências, os pesquisadores do Massachussets Institute of Technology (MIT) demonstraram que os danos cerebrais da síndrome X-Frágil poderiam ser revertidos inibindo-se uma enzima-chave do cérebro 
chamada PAK, segundo estudo publicado nesta quarta-feira na revista da Academia Nacional de Ciências (PNAS).

Ao mesmo tempo, como um campo aberto às diversas opiniões dos usuários interessados no debate, também se encontram exemplos de contestação dos achados científicos divulgados naquelas comunidades. Os conteúdos das postagens também apontam dúvidas em relação a esses achados.

Será? (maiúscula no original) Eu li essa reportagem... e tb achei interessante, apesar de ter uma abordagem unicamente psicofarmacológica, só que uma coisa me chamou muito a atenção... os testes que eles fizeram foi com ratos e até que ponto o psiquismo dos ratos tem relação com o nosso? E qual o critério que eles utilizaram pra diagnosticar autismo em ratos?

\section{Discussão dos dados}

O orkut se configurou, no caso analisado, como uma estratégia utilizada por pais e/ou cuidadores para dissolver dúvidas e formular hipóteses sobre seus parentes autistas. É interessante notar que, ainda que os usuários tenham consultado especialistas, eles procuram a rede para contato com outras pessoas que partilham a experiência de ser pai ou cuidador de um indivíduo com autismo, o que nos demonstra que o que querem ali não são dados médicos, mas acesso a fontes que lhe ofereçam outro tipo de informação: aquelas que só os que comungam a experiência de ter um parente autista podem dar e compreender.

A internet e as práticas nessa rede social parecem criar uma forma própria de relação com a medicina, na qual, ao mesmo tempo em que há respeito e interesse pelas asserções científicas sobre o autismo, há uma preponderância dos temas relativos à experiência pessoal com a doença. As comunidades estão cheias de membros leigos, são geridas sem a hierarquia dos que dominam conhecimentos médicos, mas com outras modalidades hierárquicas, como os velhos membros, ou dos membros mais presentes (aqueles que inserem postagens com maior frequência). Em geral, os que se destacam são os que mais possuem experiência sobre o assunto, e que podem orientar pais mais inexperientes.

Alguns pontos que merecem destaque sobre a dinâmica dessas comunidades analisadas: 1) a ausência de uma figura de autoridade médica permite a criação de uma autoridade baseada na experiência. Vemos surgir, entre as postagens, uma figura híbrida, que é a do leigo-especialista - indivíduo que, embora não pertença ao campo da saúde, se encontra tão envolvido com a doença que é capaz de manejar o vocabulário médico, questionar, debater e dialogar com o saber médico ${ }^{10} ; 2$ ) o conhecimento experienciado e partilhado torna-se uma fonte para a construção de teorias próprias sobre a doença e seus tratamentos mais adequados. Essas teorias e tratamentos, mais do que uma subserviência às possíveis verdades científicas em voga, são aqueles que melhor respondem às preocupações diárias, experiências e visões de mundo daqueles que lidam diretamente com a doença; 3) o poder de ação no grupo pode desembocar em atividades fora dos limites virtuais, como é o caso da convocação para passeatas e para adesão e participação de movimentos em prol do orgulho autista e dos benefícios legais que protegem esses indivíduos.

Essas são apenas tendências para aonde apontam os dados, sendo importante lembrar que esse é um campo de investigação ainda inicial no Brasil, o que revela

\footnotetext{
${ }^{10}$ A esse respeito, dados internacionais corroboram essa tendência encontrada nos dados analisados (Barker, 2008; Bromm, Tovey, 2008; Fox et al., 2005a; Gillet, 2003; Blumenthal, 2002; Hardey, 1999).
} 
a necessidade de mais pesquisas que possam contribuir para o conhecimento do papel da internet, por meio específico das redes sociais virtuais: na formação da opinião pública sobre o autismo, na troca de informações sobre a doença, no intercâmbio entre pais e cuidadores em âmbito nacional e internacional, sobre os movimentos de ativismo em andamento e, sobretudo, no que tange às novas formas de relação entre o paciente e/ou seu cuidador e responsável com os profissionais da área da saúde.

\section{Conclusões}

Muitas questões são derivadas da análise dessa parcela da opinião pública sobre o autismo no orkut, e mais do que respostas, nos conduzem a perguntas: que desafios esses atores colocam às autoridades de especialistas, e que tipo de alianças com os profissionais eles constroem? Que tipos de políticas do corpo esses grupos colocam em prática e como seus corpos são transformados como resultado disso? Quando o ativismo em saúde resulta em uma extensão da compreensão medicalizada da doença e quando ele contesta esses processos de medicalização? Como os grupos de pacientes e as instituições biomédicas intervêm nas relações sociais virtuais, tendo efeitos tanto sobre o mercado quanto sobre o Estado? Que concepções de ciência médica esses grupos de pacientes promovem e contestam, e quais visões eles põem em prática?

O que se destaca é uma situação paradoxal no que se refere ao papel da medicina, especificamente: a necessidade de desvendar e tratar a doença conduz a uma vontade de saber e divulgar achados recentes da ciência, e, por isso, há um forte apelo à autoridade médica. Ao mesmo tempo, diante da impossibilidade de chegar a ela - o que é o atual estado da arte a respeito do autismo - a doença passa a não ser decidida somente na esfera da ciência, passando, com isso, a ser alvo de discussão pública, envolvendo ativistas (pais e cuidadores de pacientes autistas), advogados, redes sociais virtuais. Temos aqui um paradoxo que atinge os portadores e familiares de doenças controversas: ao mesmo tempo em que, na biomedicina, é depositada a esperança de que se encontre a suposta verdade da doença, ela passa a não ser o lugar exclusivo onde essa veracidade é negociada, abrindo espaço para a legitimidade do conhecimento baseado na experiência do paciente e de seus cuidadores (Broom, 2005; Hardey, 1999).

Os resultados dessa investigação são um exemplo particular de um movimento mais geral, indicativo de novas formas de organização e novos objetos de luta política dos cidadãos, reunidos em função de características físicas e/ou mentais. O crescimento dos grupos de pacientes que se reúnem em torno de uma doença ou característica corporal tem sido documentado nos estudos sociológicos recentes, especialmente aqueles dedicados a compreender movimentos sociais no campo da saúde (Landzelius, 2006; Novas, 2006; Ehrenberg, 2004). Coletividades organizadas em torno de classificações biomédicas ocupam, cada vez mais, espaço real e virtual, podendo reivindicar uma influência maior na tomada de decisões sobre terapias apropriadas para as doenças, a obtenção de fundos para a pesquisa, ou, ainda, a contestação do estatuto nosológico de doenças.

Nos grupos aqui analisados, os indivíduos estão continuamente procurando explicações para suas doenças, questionando e/ou aderindo a resultados de pesquisas científicas, e aos argumentos de autoridade por elas oferecidos. Ao mesmo tempo, eles contestam informações médicas e legitimam sua própria vivência, além de ampliarem a capacidade de lidar com seus parentes acometidos pela doença. Observamos, com isso, que se tratam se grupos de biossociabilidade, organizados em torno de características biológicas e doenças específicas, como assinalou o antropólogo americano Paul Rabinow (1996).

Como se pode observar a partir dos resultados debatidos - que incluem, mas certamente não se restringem ao caso específico do autismo - as comunidades on line não são produtos passivos na internet, mas exercem posição ativa na construção de diagnósticos de doenças, bem como no modo como essas condições são experienciadas e compreendidas socialmente. 


\section{Colaboradores}

Francisco Ortega e Rafaela Zorzanelli participaram igualmente de todas as etapas da pesquisa, bem como da supervisão dos pesquisadores que auxiliaram nos processos de coleta, tabulação dos dados, reformulação dos instrumentos-piloto, análise dos dados e confecção do manuscrito. Lilian Meierhoffer, Celita Almeida e Clarissa Almeida participaram do processo de coleta de dados, da confecção e das reformulações dos instrumentos utilizados. Bárbara Costa, Beatriz Chagas e Clara Feldman participaram do processo de conferência dos dados coletados e de sua tabulação.

\section{Referências}

ARIEL, C.N.; NASEEF, R.A. (Orgs.). Voices from the spectrum: parents, grandparents, siblings, people with autism, and professionals share their wisdom. London: Jessica Kingsley, 2006.

BAGATELL, N. Orchestrating voices: autism, identity and the power of discourse. Disabil. Soc., v.22, n.4, p.413-26, 2007.

BAKER, D.L. The politics of neurodiversity: why public policy matters. Boulder: Lynne Rienner Publishers, 2011.

BARKER, K. Electronic support groups, patient-consumers, and medicalization: the case of contested illness. J. Health Soc. Behav., v.49, n.1, p.20-36, 2008.

BERGER, M.; WAGNER, T.H.; BAKER, L.C. Internet use and stigmatized illness. Soc. Sci. Med., v.61, n.8, p.1821-7, 2005.

BIEVER, C. Let's meet tomorrow in second life. New Sci., v.194, n.2610, p.26-7, 2007.

BLUME, H. Autism and the internet, or, it's the wiring, stupid. 1997. Disponível em: <http://web.mit.edu/comm-forum/papers/blume.html>. Acesso em: 12 jan. de 2012.

BLUMENTHAL, D. Doctors in a wired world: can professionalism survive connectivity? Milbank Q., v.80, n.3, p.525-46, 2002.

BROOM, A. 'Medical specialists' accounts of the impact of the internet on the doctor/ patient relationship. Health, v.9, n.3, p.319-38, 2005.

BROOM, A; TOVEY, P. The role of the internet in cancer patients engagement with complementary and alternative treatments. Health, v.12, n.2, p.139-55, 2008.

BROWNLOW, C.; O'DELL, L. Constructing an autistic identity: AS voices online. Ment. Retard., v.44, n.5, p.315-21, 2006.

CHAMAK, B. Autism and social movements: French parents' associations and international autistic individuals' organizations. Sociol. Health IIln., v.30, n.1, p.76-96, 2008.

CHAMAK, B. et al. What can we learn about autism from autistic persons? Psychother. Psychosom., v.77, n.5, p.271-9, 2008.

CHARLTON, J. Nothing about us without us: disability oppression and empowerment. Berkeley: University of California Press, 2000.

CLARKE, J.; VAN AMEROM, G. "Surplus suffering': differences between organizational understandings of Asperger's syndrome and those people who claim the 'disorder'.

Disabil. Soc., v.22, n.7, p.761-776, 2007.

Asperger's syndrome: differences between parents' understanding and those diagnosed. Soc. Work Health Care, v.46, n.3, p.85-106, 2008.

COLLINS, H.M.; EVANS, R. The third wave of science studies: studies of expertise and experience. Soc. Stud. Sci., v.32, n.2, p.235-96, 2002. 
CONRAD, P.; STULTS, C. Internet and the experience of illness. In: BIERD, C. et al. (Orgs.). Handbook of medical sociology. Nashville: Vanderbilt University Press, 2010. p.179-91.

DAVIDSON, J. Autistic culture online: virtual communication and cultural expression on the spectrum. Soc. Cult. Geogr., v.9, n.7, p.791-806, 2008.

In a world of her own: re-presenting alienation and emotion in the lives and writings of women with autism. Gender, Place Culture, v.14, n.6, p.659-77, 2007.

EHRENBERG, A. Le sujét cerebral. Esprit, v.309, n. 11, p.130-55, 2004.

EPSTEIN, S. Patient groups and health movements. In: HACKET, E.L. et al. (Orgs.). The handbook of science and technology studies. 3.ed. Cambridge: MIT Press, 2008. p.499-539.

EYAL, G. et al. The autism matrix: the social origins of the autism epidemics. Cambridge and Malden: Polity, 2010.

FOX, N.J.; WARD, K.J.; O'ROURKE, A.L. The 'expert patient': empowerment or medical dominance? The case of weight loss, pharmaceutical drugs, and the internet. Soc. Sci. Med., v.60, n.6, p.1299-309, 2005a.

Pro-anorexia, weight-loss drugs, and the internet: an 'anti-recovery' explanatory model of anorexia. Sociol. Health Illn., v.27, n.7, p.944-71, 2005b.

GANCHOFF, C. Regenerating movements: embryonic stem cells and the politics of potentiality. Sociol. Health IIIn., v.26, n.6, p.757-74, 2004.

GILLET, J. Media activism and internet use by people with HIV/Aids. Sociol. Health Illn., v.25, n.6, p.608-42, 2003.

HACKING, I. Autistic autobiography. Philos. Trans. Royal Soc. B, v.364, n.1521, p.1467-73, 2009.

HARDEY, M. Doctor in the house: the internet as a source of lay health knowledge and the challenge to expertise. Sociol. Health Illn., v.21, n.6, p.820-35, 1999.

JONES, R.; MELDAL, T.O. Social relationships and Asperger's syndrome: a qualitative analysis of first-hand accounts. J. Intellect. Dis., v.5, n.1, p.35-41, 2001.

JONES, R.S.P.; ZAHL, A.; HUWS, J.C. First-hand accounts of emotional experiences in autism: A qualitative analysis. Disabil. Soc., v.16, n.3, p.393-401, 2001.

JURECIC, A. Neurodiversity. Coll. Eng., v.69, n.5, p.421-42, 2007.

KENWAY, I.M. Blessing or curse? Autism and the rise of the internet. J. Relig. Disabil. Health, v.13, n.2, p.94-103, 2009.

LANDZELIUS, K. Introduction: patient organization movements and new metamorphoses in patienthood. Soc. Sci. Med., v.62, n.3, p.529-37, 2006.

MIAH, A.; RICH, E. The medicalization of cyberspace. New York: Routledge, 2008.

MILLER, D.; SLATER, D. The internet: an ethnographic approach. Oxford: Berg, 2000.

NOVAS, C. The political economy of hope: patients' organizations, science and biovalue. Biosocience, v.1, n.3, p.289-305, 2006.

ORSINI, M. Contesting the autistic subject: biological citizenship and the autism/ autistic movement. In: MURRAY, S.; HOLMES, D. (Orgs.). Critical interventions in the ethics of health care. London: Ashgate Publishing, 2009. p.115-30.

ORSINI, M.; SMITH, M. Social movements, knowledge and public policy: the case of autism activism in Canada and the US. Crit. Pol. Stud., v.4, n.1, p.38-57, 2010.

ORTEGA, F. The cerebral subject and the challenge of neurodiversity. Biosocience, v.4, n.4, p.425-45, 2009. 
OSTEEN, M. Autism and representation. New York: Routledge, 2008.

RABINOW, P. Artificiality and enlightenment: from sociobiology to biossociality. In: Essays on the anthropology of reason. Princenton: Princenton University Press, 1996. p.91-111.

SCHAFFER, R.; KUCZYNSKI, K.; SKINNER, D. Producing genetic knowledge and citizenship through the Internet: mothers, pediatric genetics, and cybermedicine. Sociol. Health IIIn., v. 30, n.1, p.145-59, 2008.

SEALE, C. New directions for critical internet health studies: representing cancer experience on the web. Sociol. Health IIIn., v.27, n.4, p.515-40, 2005.

SHAPIRO, J. No pity: people with disabilities forging a new civil rights movement. New York: Random House, 1993.

SILVERMAN, C. Fieldwork on another planet: social science perspectives on the autism spectrum. Bioscienci, v.3, n.3, p.325-41, 2008a.

Brains, pedigrees and promises: lessons from the politics of autism genetics. In: $\overline{G I B B O N}$, S.; NOVAS, C. (Orgs.). Biosocialities, genetics and the social sciences: making biologies and identities. London: Routledge, 2008b. p.38-55.

SINGER, J. Why can't you be normal for once in your life. In: CORKER, M.; FRENCH, S. (Orgs.). Disability discourse. Buckingham: Open University Press, 1999. p. 59-67.

WILSON, S.; PETERSON, L. The anthropology of online communities. Annu. Rev. Anthropol., v.31, p.449-67, 2002.

ORTEGA, F. et al. La construcción del diagnóstico de autismo en una red social virtual brasileña. Interface - Comunic., Saude, Educ., v.17, n.44, p.119-32, jan./mar. 2013.

Este artículo presenta resultados de una investigación realizada en una red social virtual brasileña sobre autismo. Fue investigada la opinión pública sobre el autismo por medio de las comunidades dedicadas al asunto. La opinión pública sobre determinada condición médica tiene consecuencias inmediatas sobre el enfermo y las personas implicadas directamente en cuidar de los pacientes que sufren la enfermedad. Los resultados dan informaciones sobre las representaciones de los usuarios, sobre las supuestas causas de la enfermedad, los métodos de tratamiento, las formas de activismo y de búsqueda de derechos de los portadores, y los usos paradójicos del conocimiento médico, al cual se atribuye en algunas ocasiones la posibilidad de desvelar la enfermedad, y en otras es objeto de resistencia de padres y cuidadores con base en su experiencia cotidiana con los autistas.

Palabras clave: Transtorno Autístico. Opinión pública. Red social. Trastornos psiquiátricos. 